\title{
High-resolution study of layering within the percolation and soaked facies of the Greenland ice sheet
}

\author{
Joel BROWN, ${ }^{1,2}$ Joel HARPER, ${ }^{1}$ W. Tad PFEFFER, ${ }^{3}$ Neil HUMPHREY, ${ }^{4}$ \\ John BRADFORD ${ }^{2}$
}

\author{
${ }^{1}$ Department of Geosciences, University of Montana, 32 Campus Drive, Missoula, MT 59812, USA \\ ${ }^{2}$ Center for Geophysical Investigation of the Shallow Subsurface, Boise State University, 1910 University Drive, \\ Boise, ID 83725, USA \\ E-mail: jbrown@cgiss.boisestate.edu \\ ${ }^{3}$ Institute of Arctic and Alpine Research and Department of Geological Sciences, University of Colorado at Boulder, Boulder, \\ CO 80303-0450, USA \\ ${ }^{4}$ Geology and Geophysics Department 3006, University of Wyoming, Laramie, WY 82071, USA
}

\begin{abstract}
Within the percolation and soaked facies of the Greenland ice sheet, the relationship between radar-derived internal reflection horizons and the layered structure of the firn column is unclear. We conducted two small-scale ground-penetrating radar (GPR) surveys in conjunction with $10 \mathrm{~m}$ firn cores that we collected within the percolation and soaked facies of the Greenland ice sheet. The two surveys were separated by a distance of $\sim 50 \mathrm{~km}$ and $\sim 340 \mathrm{~m}$ of elevation leading to $\sim 40$ days of difference in the duration of average annual melt. At the higher site ( 1997 $\mathrm{m}$ a.s.l.), which receives less melt, we found that internal reflection horizons identified in GPR data were largely laterally continuous over the grid; however, stratigraphic layers identified in cores could not be traced between cores over any distance from 1.5 to $14.0 \mathrm{~m}$. Thus, we found no correlation between firn core stratigraphy observed directly and radar-derived internal reflection horizons. At the lower site ( $\sim 1660 \mathrm{~m}$ a.s.l.), which receives more melt, we found massive ice layers $>0.5 \mathrm{~m}$ thick and stratigraphic boundaries that span $>15 \mathrm{~m}$ horizontally. Some ice layers and stratigraphic boundaries correlate well with internal reflection horizons that are laterally continuous over the area of the radar grid. Internal reflection horizons identified at $\sim 1997 \mathrm{~m}$ a.s.l. are likely annual isochrones, but the reflection horizons identified at $\sim 1660 \mathrm{~m}$ a.s.l. are likely multi-annual features. We find that mapping accumulation rates over long distances by tying core stratigraphy to radar horizons may lead to ambiguous results because: (1) there is no stratigraphic correlation between firn cores at the $1997 \mathrm{~m}$ location; and (2) the reflection horizons at the $1660 \mathrm{~m}$ location are multi-annual features.
\end{abstract}

\section{INTRODUCTION}

In the dry-snow facies of the Greenland ice sheet (GrlS), radar-derived internal reflecting horizons in the firn are associated primarily with density contrasts across yearly summer surfaces where high-density wind-scoured surfaces overlay a layer of faceted grains (e.g. Arcone and others, 2004). The dry-snow facies of the GrlS is the region above the dry snowline where melt is negligible (Benson, 1960). As melt is negligible and overburden is the primary driver of densification through the firn column in the dry-snow facies, density variations that are present in the annually accumulated snow surface layer are preserved in the firn column. Internal reflection horizons imaged with ground-penetrating radar (GPR) in firn are generally accepted to be isochrones (e.g. Vaughan and others, 1999; Helm and others, 2007). The apparent depth to these reflection horizons has been used successfully to map variations in accumulation rates between firn cores in Antarctica (e.g. Arcone and others, 2004; Spikes and others, 2004). In regions where surface melt is not negligible, however, the processes of infiltration and refreezing change the internal density structure of the firn column heterogeneously. These changes in the intralayer density structure affect the internal reflections recorded with GPR and may also affect the isochronal nature of layering in the firn column.

Within the accumulation zone of the GrIS, the percolation facies (by definition) covers all areas where melt occurs, yet the wetting front does not reach the previous summer surface (Benson, 1960). Regions of the accumulation area where wetting fronts do reach the previous summer surface, thus soaking the seasonal snow layer, are within the soaked facies. The percolation facies covers more than one-third of the total area of the GrIS (Nghiem and others, 2005); the soaked facies is less extensive, covering $<10 \%$ of the area of the percolation facies (estimated from fig. 48 in Benson, 1960). Both facies are annually transient; the boundary between them is also transient and has no explicit surface expression. Thus we do not distinguish between them herein; instead we use the term 'percolation zone' to encompass both facies. Within the percolation zone, infiltration of surface melt redistributes mass vertically and horizontally. The result of this redistribution of mass varies with the amount of melt, the cold content of the firn and the accumulation rate at the location.

Past studies have shown that at $\sim 1940 \mathrm{~m}$ elevation upstream of Jakobshavn Isbræ in the percolation zone of western Greenland (Fig. 1), summer melt greatly modifies the surface snow layer (Pfeffer and Humphrey, 1998; Scott and others, 2006b; Parry and others, 2007). In early spring, before the onset of melt, dry low-density snow with small density variations (due to buried wind-scoured surfaces) overlies a heterogeneous layer of firn with ice pipes and ice layers (Scott and others, 2006a,b; Helm and others, 2007; Parry and others, 2007; Dunse and others, 2008). At the end 


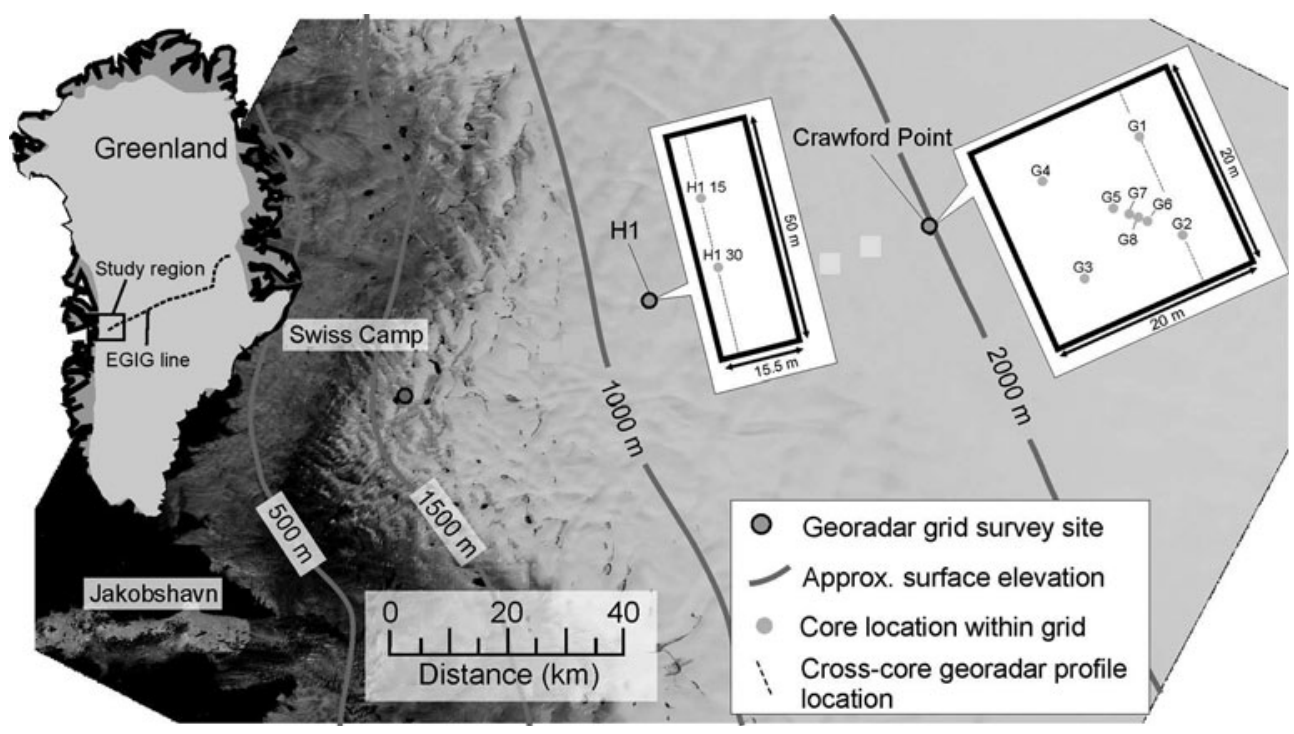

Fig. 1. Advanced Spaceborne Thermal Emission and Reflection Radiometer (ASTER) image with locations of Crawford Point and H1 shown. GPR grid size and orientation along with core locations are shown for both study sites. Solid lines are approximate elevation contours (Bamber and others, 2001). Dashed lines show locations of GPR profiles shown in Figures 3 and 5; all GPR data were collected parallel to these lines.

of the summer melt season, the snow layer is more complex, with ice pipes and ice layers distributed non-uniformly (Jezek and others, 1994; Pfeffer and Humphrey, 1998; Parry and others 2007). At lower elevations ( 1800 to $\sim 1450 \mathrm{~m}$ ), water from increased melting saturates yearly accumulated snow, penetrates the previous summer surface and reaches depths of 2-4 m (Braithwaite and others, 1994; Pfeffer and Humphrey, 1998).

As percolation of surface melt can change the physical characteristics of annual layering and internal reflection horizons in many different ways through the percolation zone, studies combining GPR data and layer stratigraphy in the percolation zone yield a wide range of results. Along a short $5 \mathrm{~m}$ profile recorded to $\sim 10 \mathrm{~m}$ depth at $\sim 1940 \mathrm{~m}$ elevation, Scott and others (2006b) did not resolve any continuous internal reflection horizons. However, on a longer profile $(1500 \mathrm{~m})$ they found a semicontinuous reflection horizon at $\sim 2 \mathrm{~m}$ depth. It is likely that laterally continuous reflection horizons were missed in the $5 \mathrm{~m}$ profile because they used $0.5-1.5 \mathrm{~m}$ trace spacing with $13 \mathrm{GHz}$ radar, where the Nyquist sampling distance is $<0.01 \mathrm{~m}$ for this frequency (Nyquist, 1928; Dunse and others, 2008). In the $1500 \mathrm{~m}$ survey the horizon was likely identified because a five-trace running mean was applied to the data during acquisition, effectively increasing the footprint of each recorded trace. In a later survey, Scott and others (2006a) interpreted high levels of radar backscatter as previous summer surfaces; between $\sim 2350$ and $\sim 1940$ m elevation the number of identifiable backscatter peaks diminished from five annual layers to a single reflection representing the last summer surface. Also at $\sim 1940 \mathrm{~m}$, Dunse and others (2008) used GPR to identify six internal reflection horizons within the upper $10 \mathrm{~m}$ of firn. It is likely that they were able to identify more layers at $\sim 1940$ m elevation because they used lower-frequency radar $(500 \mathrm{MHz})$ than the $2-18 \mathrm{GHz}$ radar used by Scott and others (2006a). Dunse and others (2008) correlated the reflection horizons to ice layers or previous summer surfaces identified in firn cores by Scott and others (2006a) and Parry and others (2007). Further, they interpreted summer melt conditions that potentially result in each identified layer. However, because melt-induced diagenic features in the percolation zone of the GrIS are rarely laterally continuous even over short distances (Parry and others, 2007), it is unclear if internal reflection horizons can be correlated to stratigraphic layers or sequences of stratigraphic layers identified in firn cores. Further, it is unclear where (or if) internal reflection horizons identify spatially continuous impermeable ice layers which may indicate the potential for runoff to occur.

Here we investigate the continuity of layer stratigraphy in the firn column of the percolation zone, the relationship between layer stratigraphy and internal reflection horizons, and the information that internal reflection horizons reveal about the firn column. We present and analyze threedimensional (3-D) GPR grid surveys with high spatial resolution collected in conjunction with multiple $\sim 10 \mathrm{~m}$ firn cores. Data were collected at two sites, one near the top of the percolation zone and one near the transition between percolation facies and soaked facies.

\section{METHODS}

\subsection{Study sites}

We collected data at two sites in the percolation zone of the GrIS near the Expéditions Glaciologiques Internationales au Groenland (EGIG) line (Fig. 1). Our sites span the region studied by Braithwaite and others (1994), Pfeffer and Humphrey (1998) and others (e.g. Scott and others, 2006a,b; Helm and others, 2007; Parry and others, 2007; Dunse and others, 2008). At Crawford Point, near the top of the percolation zone at $1997 \mathrm{~m}$ a.s.l., there were an average of 12.79 melt days $\mathrm{a}^{-1}$, with a range of $0-48$ melt days $\mathrm{a}^{-1}$, between 1979 and 2007 (W. Abdalati, http://nsidc.org/data/ nsidc-0218.html). At $\mathrm{H1}(\sim 1660 \mathrm{~m})$ there were an average of 53.03 melt days $\mathrm{a}^{-1}$ with a range of $16-85$ melt days $\mathrm{a}^{-1}$ over the same period (Fig. 2). The sites are upstream from Jakobshavn Isbræ and are separated by $\sim 50 \mathrm{~km}$ horizontally and $\sim 300 \mathrm{~m}$ in elevation. 


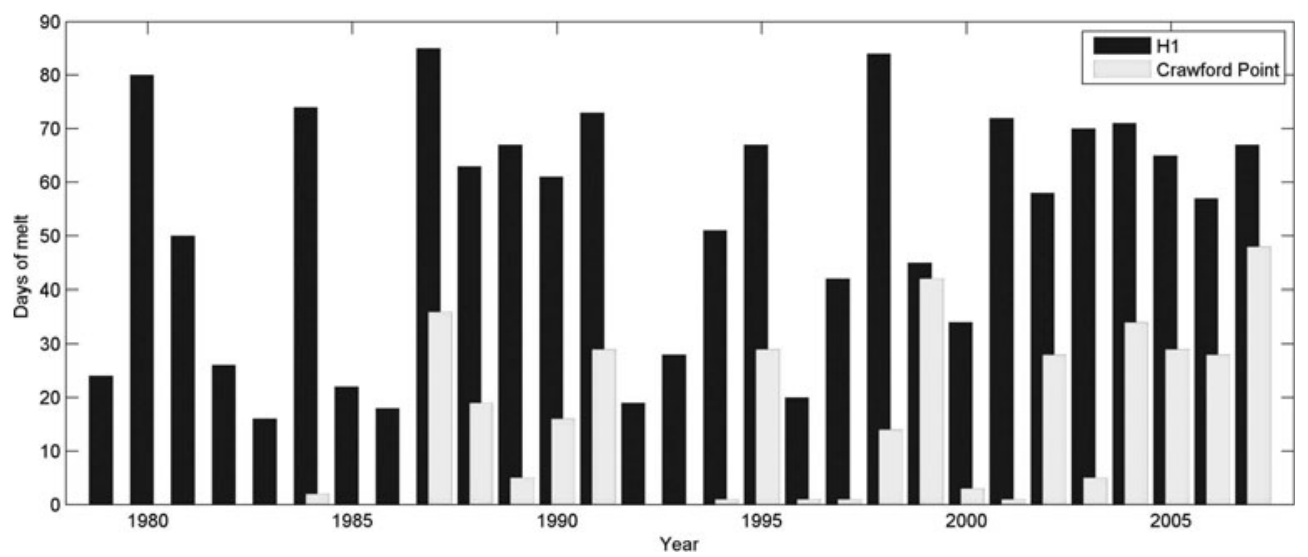

Fig. 2. Total number of melt days for Crawford Point (light) and H1 (dark) from 1979 to 2007 (Abdalati, http://nsidc.org/data/ nsidc-0218.html)

\subsection{3-D common-offset GPR surveys}

In late June 2007 we used a Sensors and Software pulseEKKO Pro GPR system with $500 \mathrm{MHz}$ antennae to collect data in a $20 \mathrm{~m} \times 20 \mathrm{~m}$ grid at Crawford Point. We collected 104 transects with $\sim 0.20 \mathrm{~m}$ horizontal line spacing. For each transect, we recorded a trace (consisting of 16 stacked traces) every $0.1 \mathrm{~s}$ while walking at a constant pace. This resulted in an average trace spacing of $0.13 \mathrm{~m}$, a maximum trace spacing of $0.165 \mathrm{~m}$, a minimum trace spacing of $0.096 \mathrm{~m}$ and a standard deviation of $0.014 \mathrm{~m}$. As triggering for trace sampling was based on time and not distance, trace spacing was determined for each line by dividing the total distance traveled by the number of traces recorded along that distance. The $500 \mathrm{MHz}$ radar used at Crawford Point had a vertical resolution of $\sim 0.1 \mathrm{~m}$ (onequarter wavelength resolution for $2.0 \mathrm{~m} \mathrm{~ns}^{-1}$ velocity) and a horizontal resolution (first Fresnel zone) of $\sim 0.5$ to $\sim 1.5 \mathrm{~m}$ at $\sim 1$ and $\sim 10 \mathrm{~m}$ depth, respectively.

In May 2008 we used a Sensors and Software pulseEKKO Pro GPR system with $200 \mathrm{MHz}$ antennae to collect data in a $50.0 \mathrm{~m} \times 15.5 \mathrm{~m}$ grid at $\mathrm{H} 1 \quad(1650 \mathrm{~m}$ a.s.l.). We used the $200 \mathrm{MHz}$ antennae at this site because the $500 \mathrm{MHz}$ signal did not penetrate to the desired $\sim 10 \mathrm{~m}$ firn depth. We collected 35 transects with $0.5 \mathrm{~m}$ horizontal line spacing. We used an odometer wheel to record a trace (consisting of eight stacked traces) every $0.1 \mathrm{~m}$. Owing to slipping, buildup of snow and the uneven snow surface, the actual trace spacing was $0.12-0.10 \mathrm{~m}$, with a calculated average of $0.115 \mathrm{~m}$ and a standard deviation of $0.002 \mathrm{~m}$. The $200 \mathrm{MHz}$ radar used at $\mathrm{H} 1$ had a vertical resolution of $\sim 0.25 \mathrm{~m}$ and a horizontal resolution of $\sim 0.7$ to $\sim 2.2 \mathrm{~m}$ at 1 and $10 \mathrm{~m}$ depth, respectively.

For both sets of data we applied a low-pass filter with a cut-off frequency of one-half the peak frequency to reduce very low-frequency noise, flattened all traces so that the first arrival was at time zero, and used a time ${ }^{1.2}$ gain function to account for spherical spreading and attenuation of the signal. We interpolated along our transects to create an even grid spacing, then interpolated across transects to create a 3-D data grid with a directional spatial sampling ratio of approximately $4: 3$ at Crawford Point and 5:1 at $\mathrm{H} 1$. Further, line spacing was approximately one-half wavelength for each survey. The low spatial sampling ratios and small line spacing allow us to interpolate between transects without directionally aliasing our grid.

\subsection{Core stratigraphy}

We collected a total of ten cores to $\sim 10 \mathrm{~m}$ depth within the two GPR grids, eight at Crawford Point and two at H1 (Fig. 1). Cores were drilled using a Kovacs coring drill with a power head and $\sim 9 \mathrm{~cm}$ inside diameter. Core depths are measured from the surface which was loose snow at both locations, so depths are not exact $( \pm 5 \mathrm{~cm})$. We logged the cores in the field, recording density, grain size and firn type, and estimated percent ice content. Density measurements were made approximately every $0.15-0.40 \mathrm{~m}$. Firn type, grain size and estimated ice percent were recorded layer by layer. Herein we distinguish between seven metamorphic firn types with varying diagenesis: (1) dry snow: layer above most recent melt surface with no noticeable amount of liquid water content; (2) wet snow: layer infiltrated by current season's melt with a noticeable amount of liquid water content; (3) faceted crystals: buried layer of dry faceted ice crystals; (4) wetted facets: faceted crystals with signs of previous wetting (i.e. slight rounding of facets, partially necked); (5) wetted firn: either firn with evidence of previous wetting (i.e. rounded grains, heavily necked) or frozen slush (same characteristics); (6) unwetted firn: firn with no evidence of previous wetting (i.e. angular ice grains, open pore space); and (7) ice layer or ice pipe: any layer that is pure ice. For layers that had inclusions of ice lenses or ice pipes, we visually estimated the percent pure ice for that layer.

\subsection{Core/GPR comparisons}

At both locations we collected GPR data prior to collecting cores. We converted GPR two-way travel time (TWT) to depth using average radar propagation velocities (2.10 $\mathrm{m} \mathrm{ns}^{-1}$ for Crawford Point, $1.96 \mathrm{~m} \mathrm{~ns}^{-1}$ for $\mathrm{H} 1$ ) calculated using a two-phase mixing equation (Harper and Bradford, 2003). For each site we used the mean core density from all of the cores to calculate the average propagation velocity for that location. Average propagation velocities varied among cores by $0.07 \mathrm{~m} \mathrm{~ns}^{-1}$ at Crawford Point and by $<0.01 \mathrm{~m} \mathrm{~ns}^{-1}$ at $\mathrm{H} 1$. At Crawford Point, where core data span multiple transects $(\sim 50$ transects) we picked high-amplitude internal reflection horizons in 82 transects of the GPR data, converted core depths to TWT and plotted the picks with core data that include ice layers and different diagenic firn types. At $\mathrm{H} 1$, both cores are located along a single transect, so 3-D mapping of internal refection horizons is not needed to trace layers between cores. Since 


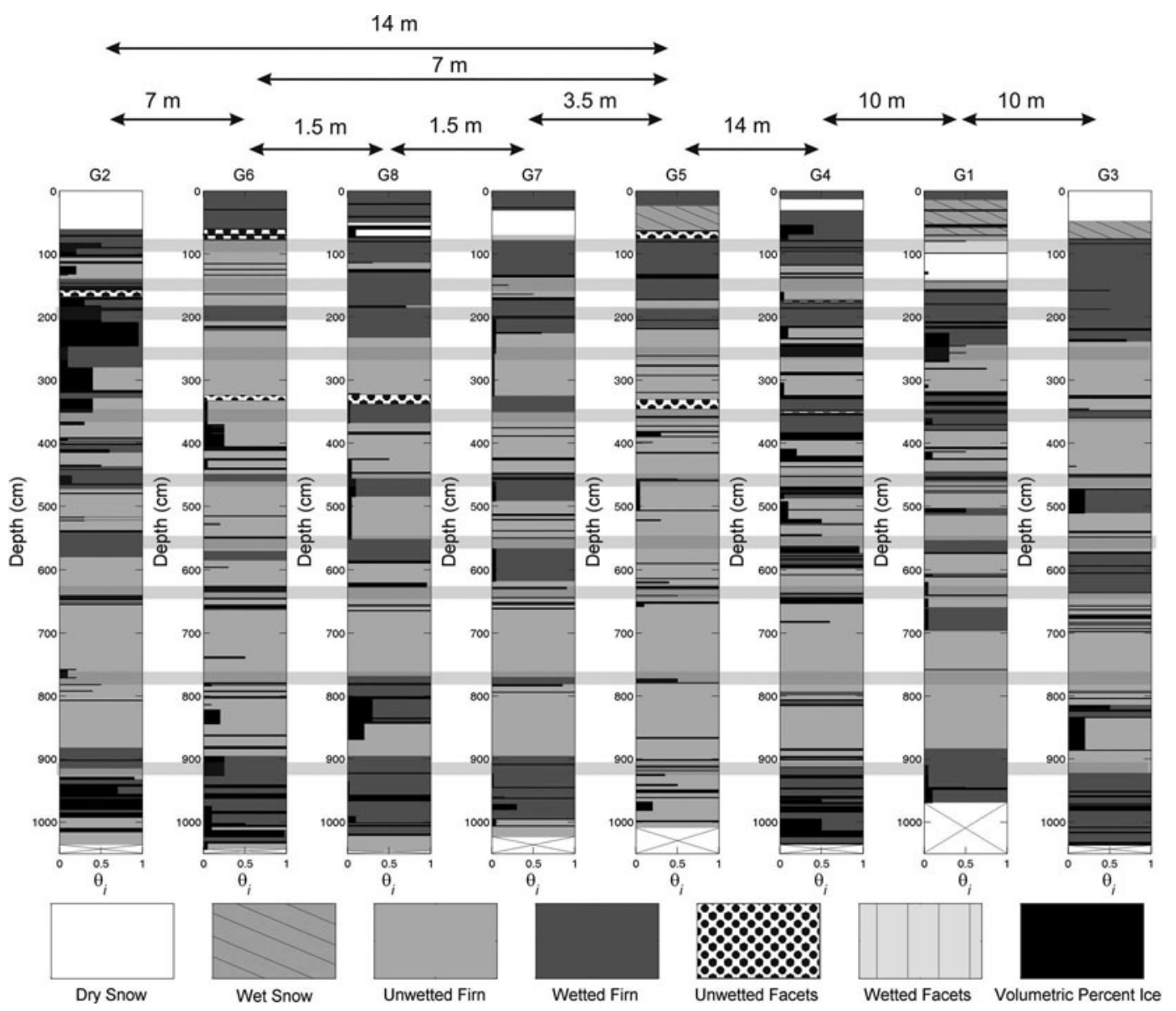

Fig. 3. Core data from eight cores drilled at Crawford Point. Distances between cores are shown at the top of the figure; the colors/patterns corresponding to firn types are shown in the legend at the bottom. Light gray lines show the approximate depths of semicontinuous GPR internal reflection horizons. Black bars show approximate volumetric percent of ice at depth.

the wavelengths of radar used in this study are much greater than firn grain size, it is likely that density variations within the firn column are the main source of radar reflections (Tiuri and others, 1984). As density measurements were conducted on each extracted core segment and most core segments consisted of multiple stratigraphic layers, the measured density vs depth profiles do not accurately reflect density variations of each stratigraphic layer in the firn column. We therefore restrict our radar/core analysis to stratigraphic layers and layer boundaries (boundaries between the seven metamorphic firn types listed in section 2.3).

\section{RESULTS}

\subsection{Firn cores}

At Crawford Point, we collected eight firn cores early in the melt season on three days in early July 2007: 1 July (G1-G5), 6 July (G6 and G7) and 10 July (G8). New infiltration and refreezing were seen in the top snow layer. In limited cases, we observed infiltration into the firn as a consequence of piping. The cores revealed a large degree of variability in stratigraphic layering over short distances (Fig. 3). Unwetted firn formed the largest portion of the cores; layers of wetted firn or frozen slush up to $\sim 1.5 \mathrm{~m}$ thick were found in every core. Ice layers, ice pipes and clusters of ice pipes were present within both wetted and unwetted firn and at some boundaries between wetted and unwetted firn. We identi- fied faceted grains in six of the eight cores and dry-snow layers in six of the eight cores. Within the upper layer of G5, G1 and G3 we also observed wet snow.

The $\mathrm{H} 1$ cores ( $\mathrm{H} 1-15$ and $\mathrm{H} 1-30)$ were collected on 27 May 2008 after the first onset of melt but following an interval of cold temperatures and new snow accumulation, so the surface layer was the winter accumulation layer with no melt-related diagenic changes. This surface layer consisted of a wind-scoured surface underlain by $\sim 0.8 \mathrm{~m}$ of dry snow with faceted grains below the dry snow to $\sim 1 \mathrm{~m}$ (Fig. 4). Under the faceted grains was a thin ice layer $\sim 0.1 \mathrm{~m}$ thick, with a layer of wetted facets below the ice layer. A layer of wetted firn $\sim 2 \mathrm{~m}$ thick was below this surface. There was a massive ice layer $0.55-0.60 \mathrm{~m}$ thick located at $\sim 3.5 \mathrm{~m}$ depth in both cores. The cores had another massive ice layer $>0.6 \mathrm{~m}$ thick that extended from $\sim 7.5$ to $\sim 8.1 \mathrm{~m}$ depth. Other massive ice layers within the cores were $0.3-0.5 \mathrm{~m}$ thick, but they did not appear in both cores. Nine thinner ice layers appeared to be continuous across the cores between 1.2 and $9.0 \mathrm{~m}$ depth. Near the end of both cores (at $\sim 10 \mathrm{~m}$ depth) there was a layer of unwetted firn that extended to the end of the core at 10.45 and $10.33 \mathrm{~m}$ for cores $\mathrm{H} 1-15$ and $\mathrm{H} 1-30$, respectively. Overall, the cores at $\mathrm{H} 1$ had a greater percentage of wetted firn and ice $(>80 \%)$ than those at Crawford Point $(<45 \%)$.

\subsection{3-D GPR}

At Crawford Point, our $500 \mathrm{MHz}$ common-offset profiles show laterally continuous internal reflection horizons at 


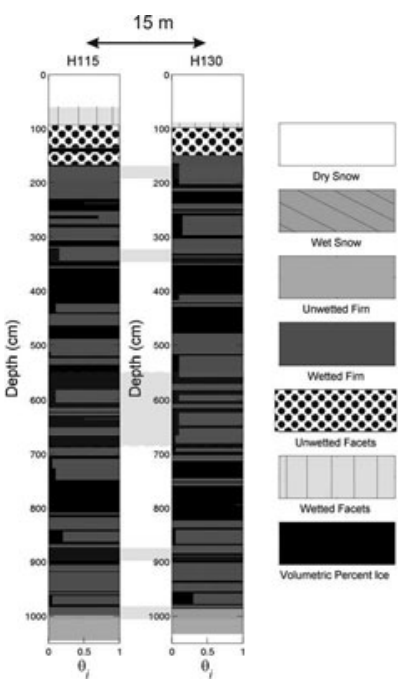

Fig. 4. Core data from both cores at $\mathrm{H} 1$. The distance between the cores is $15 \mathrm{~m}$. The colors/patterns corresponding to firn types are shown in the legend at the right. Black bars show approximate volumetric percent of ice at depth.

nine times between 8 and 95 ns (Fig. 5a). Identification of all of these layers from any single transect is highly problematic due to inconsistency in reflection amplitude and apparent 'holes' in each reflection horizon. We therefore identified laterally continuous reflection horizons by combining layer picks from 82 individual transects (Fig. 5b). Owing to a recording error, the other 22 recorded transects lost data below $\sim 8 \mathrm{~m}$ depth and were not used to pick layers. Above $8 \mathrm{~ns}$, as well as between 48 and $65 \mathrm{~ns}$, there are several discontinuous layers. Between 35 and $48 \mathrm{~ns}$ there was a region of high reflectivity with no obvious internal structure. The region between 25 and $35 \mathrm{~ns}$ had very few reflections. Although there were laterally continuous horizons throughout the grid, all of the horizons had holes (regions where reflections were not identifiable in either in-line or cross-line directions) and all of the horizons had lateral variations in amplitude. Even so, we use the term 'laterally continuous' herein to refer to these mostly continuous internal reflection horizons. Figure 6 shows an interpolated surface (light blue) picked from the horizon with the highest level of continuity (at $\sim 15 \mathrm{~ns}$ ). This surface is well defined through 82 separate transects (Fig. 5b) and reveals small-scale undulations in the surface as well as gaps in the reflection horizon. Some of the gaps in the reflection horizon are $>2 \mathrm{~m}$ across. At $\mathrm{H1}, 200 \mathrm{MHz}$ common-offset radar revealed laterally continuous internal reflection horizons at six depths between 15 and $120 \mathrm{~ns}$ (Fig. 7). There is a region of high reflectivity between $\sim 40$ and $\sim 80 \mathrm{~ns}$ where internal reflection horizons are continuous across $5-50 \mathrm{~m}$ in some GPR profiles, but are completely absent from profiles separated by as little as $2-5 \mathrm{~m}$.

\section{DISCUSSION}

At Crawford Point we found no stratigraphic correlation between eight firn cores over any distance between 1.5 and $14.0 \mathrm{~m}$. However, within the 3-D GPR grid data we identified nine internal reflection horizons in the top $\sim 9.8 \mathrm{~m}$. Although none of the horizons was completely laterally continuous,
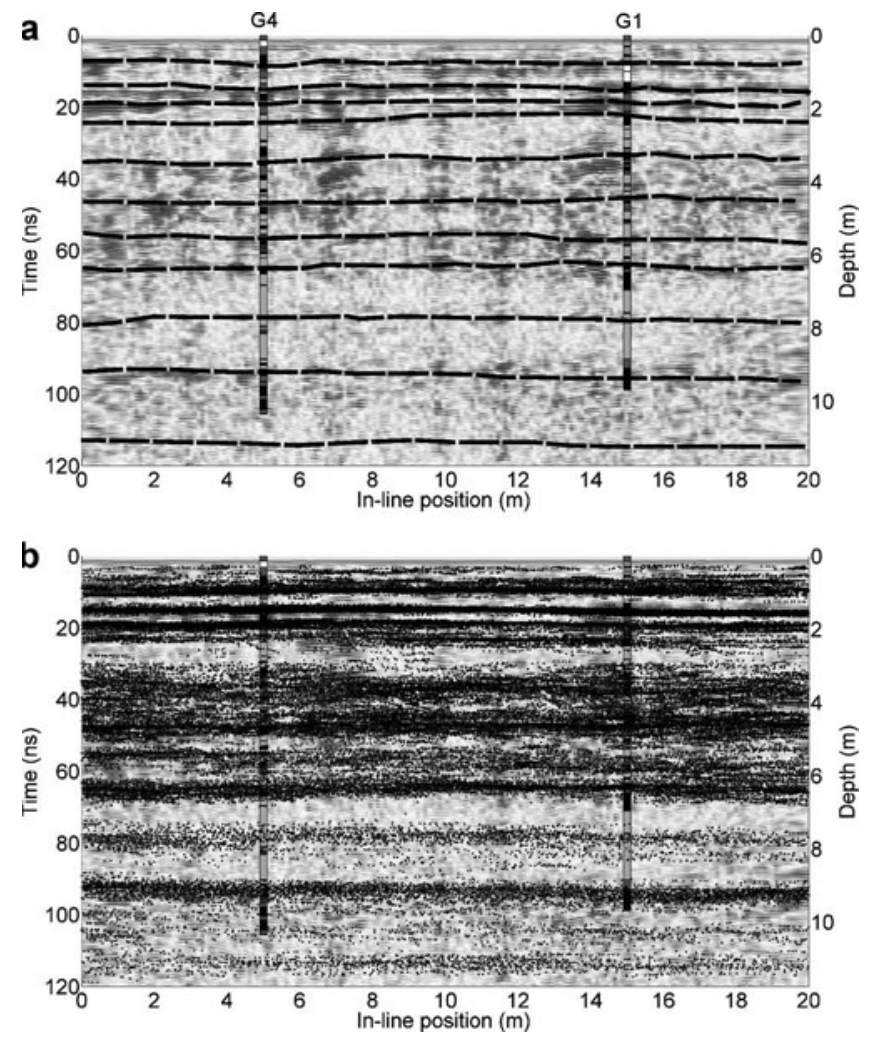

Fig. 5. (a) GPR profile from Crawford Point $(500 \mathrm{MHz})$ with two core intersections shown. Different colors in the cores represent firn/snow types. Black dashed lines show locations of semicontinuous internal reflection horizons. (b) All of the laterally coherent high-reflectivity picks made on 82 transects within the Crawford Point GPR grid overlain on the radar profile in (a). As internal reflection horizons are not completely laterally continuous, these picks form the basis of our interpretation of internal reflection horizons.

they each constitute an easily identifiable surface in both in-line and cross-line directions. By comparing identified reflection horizons with core data (Figs 3 and 6), it is apparent that internal reflection horizons do not correlate with any single stratigraphic layer or sequence of layers identified in the cores. For example, there are no laterally continuous ice layers, no common transitions from wetted to

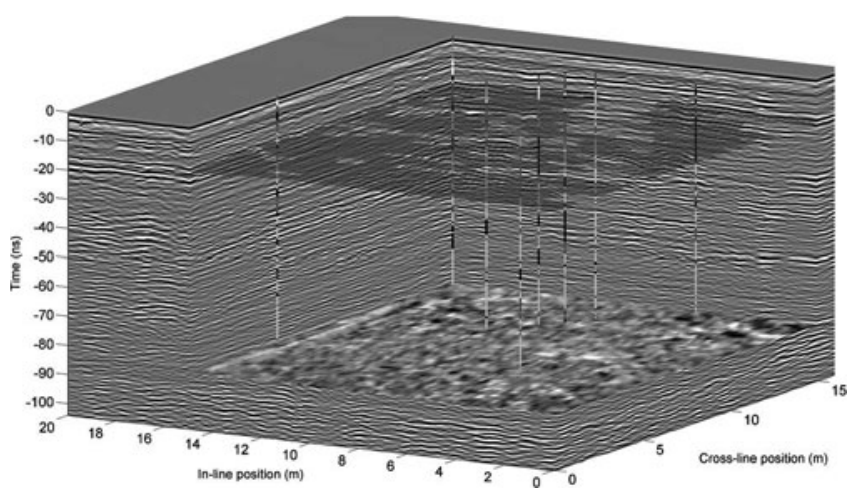

Fig. 6. GPR 3-D grid from Crawford Point with all core locations shown. Different colors in the cores represent firn/snow types. We show a mapped layer with holes (light blue) at $\sim 1.5 \mathrm{~m}$ depth. This figure shows the overall lateral continuity of the internal reflection horizons and the lack of continuity across cores. 


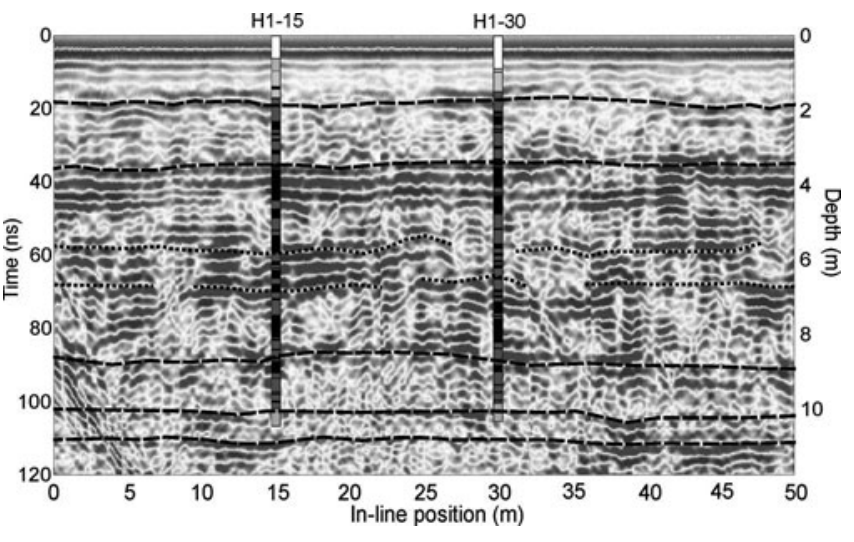

Fig. 7. GPR profile from $\mathrm{H} 1(200 \mathrm{MHz})$ with both core intersections shown. Different colors in the cores represent firn/snow types. Black dashed lines show locations of continuous internal reflection horizons. Black dotted lines show locations of horizons from massive regions of high reflectance; these horizons are not laterally continuous over the area of the grid.

unwetted firn, or any other stratigraphic features that can be interpreted as the source of laterally continuous reflection horizons. The variations in amplitude observed in the reflection horizons may be due to lateral variations in density contrasts, layer thickness or configuration of thinlayer packages.

Our results at Crawford Point are consistent with previous studies which show that, although ice lenses and ice pipes are distributed heterogeneously throughout the near-surface snow and firn (Parry and others, 2007), internal reflection horizons are usually related to vertically bounded sequences of ice-layer clusters (Dunse and others, 2008) at $\sim 1875 \mathrm{~m}$ elevation along the EGIG line. Our cores showed that the distribution of ice layers and ice pipes is laterally and vertically heterogeneous when measured over the crosssectional area of a typical core $\left(\sim 6 \times 10^{-3} \mathrm{~m}^{2}\right)$. However, since the internal reflection horizons were laterally continuous over tens of meters, we believe that there is preferential vertical distribution of ice layers and ice pipes as measured over the footprint of the GPR $\left(\sim 0.65 \mathrm{~m}^{2}\right.$ at the surface, $\sim 4.25 \mathrm{~m}^{2}$ at $1 \mathrm{~m}$ depth, calculated using the equation in fig. 14 of Annan and Cosway, 1992). It is well established that previous wind-blown surfaces restrict vertical flow and enhance lateral flow of meltwater (Bøggild, 2000; Parry and others, 2007). It is also established that grain-size differences can create boundaries that inhibit the vertical flow of small amounts of water. Both wind-blown surfaces and grain-size boundaries are present throughout annular layers (Benson, 1960; Parry and others, 2007); however, within $\sim 20 \mathrm{~km}$ and $50 \mathrm{~m}$ elevation of Crawford Point, $18 \%$ of identified ice layers are associated with fineto-coarse grain boundaries (Parry and others, 2007). Benson (1960) describes how these grain-size boundaries are often associated with fine-grained winter snow accumulation overlying a coarser-grained less dense layer that accumulates in the short fall season. He further states that in regions of melt, this discontinuity is often slightly above the summer melt surface. Since these discontinuities which are associated with previous summer surfaces can act as aquitards, we suggest that diagenic features such as ice layers, ice pipes, faceted grains and wetted firn occur preferentially near density boundaries delineated by previous summer surfaces at Crawford Point. Further, we contend that this preferential distribution is not apparent over the area sampled by a single core, whereas over the footprint of the radar (which is approximately four orders of magnitude greater in area than the core) the preferential distribution of melt-induced diagenic features is apparent.

Although the vertical resolution of the radar used at Crawford Point was $\sim 0.1 \mathrm{~m}$ and the vertical resolution of the radar used at $\mathrm{H} 1$ was $\sim 0.25 \mathrm{~m}$, there is a stronger correlation between laterally continuous internal reflection horizons and core stratigraphy at $\mathrm{H} 1$ than at Crawford Point. This is probably because total annual melt is greater at $\mathrm{H} 1$ than at Crawford Point. In years when melt occurs at both $\mathrm{H} 1$ and Crawford Point (Fig. 2), there is an average of $\sim 14.5$ times as many melt days at $\mathrm{H} 1$ as at Crawford Point (W. Abdalati, http://nsidc.org/data/nsidc-0218.html). The relatively large amount of melt and infiltration creates massive ice layers $\sim 0.5 \mathrm{~m}$ thick and a firn stratigraphy that is composed mostly of wetted firn and ice layers (Braithwaite and others, 1994; Pfeffer and Humphrey, 1998).

At $\mathrm{H} 1$ we can correlate three laterally continuous internal reflection horizons to significant transitions in firn stratigraphy: (1) the transition from faceted grains to wetted firn at $\sim 1.5 \mathrm{~m}$; (2) the massive ice layer at $\sim 3.5-4.0 \mathrm{~m}$; and (3) the transition from wetted firn to non-wetted firn at $\sim 10 \mathrm{~m}$. These are all likely sources of internal reflection horizons. The corresponding reflection horizons are also the most laterally consistent through the data. The volume between the massive ice layer (2) and the non-wetted firn (3) contains many stratigraphic layers that could be laterally continuous across the cores, including the massive ice layer observed in each core at $\sim 7.5 \mathrm{~m}$ depth. However, between the reflection horizons at $\sim 4.1$ and $\sim 11.6 \mathrm{~m}$, there are only two reflection horizons, both of which are laterally discontinuous across the grid, although they do appear in most transects. Because the reflection horizons found at this depth are laterally discontinuous, it is likely that the firn stratigraphy between 4 and $10 \mathrm{~m}$ is highly laterally heterogeneous and that the apparent stratigraphic correlations between 4 and $10 \mathrm{~m}$ across the cores at $\mathrm{H} 1$ are due to: (1) the simple layer stratigraphy (only wetted firn and ice) found in the cores; and (2) the limited number of cores logged in the grid region. However, it is possible that the vertical resolution of the $200 \mathrm{MHz}$ radar $(\sim 0.25 \mathrm{~m})$ is too coarse to identify individual layers in this region unless the layers are massive.

If we assume that the 2007/08 winter accumulation at $\mathrm{H} 1$ ( $\sim 0.328 \mathrm{~m}$ w.e., defined by the non-wetted snow layer) is roughly average and that the summer accumulation increases the total accumulation by $55 \%$, as Parry and others (2007) observed at $\sim 1875 \mathrm{~m}$ a.s.I. along the EGIG line, then the total yearly accumulation is roughly $0.51 \mathrm{~m}$ w.e. Below the last melt surface $(\sim 1 \mathrm{~m}$ depth) we measured an average firn density of $\sim 635 \mathrm{~kg} \mathrm{~m}^{-3}$. Using this average firn density, we calculated that the thicknesses between surfaces that we identified in the GPR are roughly equivalent to 1.7-3.8 years of accumulation (similar calculations for Crawford Point give a range of $0.94-1.14$ years of accumulation for each internal reflection horizon). This estimate assumes that no meltwater leaves the area as runoff or infiltrates past the maximum core depth, so it should be considered a lower bound. Under these conditions, it is unlikely that the reflecting horizons at $\mathrm{H} 1$ occur at previous summer surfaces, but instead they likely occur at density boundaries that are formed by multiyear variations in melt (variations in overall melt that occur 
slowly over 2-10 years as opposed to single melt events that occur in a single season).

Arcone and others (2004), among others, have successfully traced identifiable internal reflection horizons across long distances $(>90 \mathrm{~km})$, tying firn-core depth/age relationships to each other in Antarctica, implying that this would also work in the dry-snow facies of the GrIS. The ability to tie distant cores together with GPR data is important for understanding spatial variations in accumulation rates and determining accumulation rates in regions where no cores exist (Bales and others, 2009). In the percolation zone, however, we find potential problems with determining accumulation rates by tying cores to GPR data. In highelevation portions of the percolation zone like Crawford Point ( 1997 ma.s.l.), firn stratigraphy is complex and laterally heterogeneous, but reflection horizons are probably isochrones and seasonally variable signals are identifiable. However, the load vs depth (calculated from core density profiles) varies by an average of 20\% (1.5-14.0 m) and affects radar velocities by $\sim 3 \%$ to $7 \%$ over short distances $(1.5-$ $14.0 \mathrm{~m}$ ). Thus, the apparent depth of layers is affected to the same degree. Since we use a constant velocity to convert radar travel time to depth, correlation between cores and radar reflection horizons across the grid at Crawford Point should only be considered approximate. However, because there was no cross-core stratigraphic correlation at Crawford Point, detailed correlation between reflection horizons and core stratigraphy would not be possible even with totally accurate depth conversions. The effects of the velocity variation on the average depth of reflection horizons may be limited by spatially smoothing the recorded signal and accurately determining the average velocity vs depth over the corresponding distance. At H1 ( 1660 ma.s.l.), internal reflection horizons likely represent multiple years of accumulation, and stratigraphic features (e.g. massive ice layers) may form over multiple years. This is probably because total annual melt is greater at $\mathrm{H} 1$ than at Crawford Point. In years when melt occurs at both $\mathrm{H} 1$ and Crawford Point (Fig. 2), there is an average of $\sim 14.5$ times as many melt days at $\mathrm{H} 1$ as at Crawford Point (W. Abdalati, http://nsidc.org/data/nsidc0218.html). The relatively large amount of melt and infiltration creates massive ice layers $\sim 0.5 \mathrm{~m}$ thick and a firn stratigraphy that is composed mostly of wetted firn and ice layers (Braithwaite and others, 1994; Pfeffer and Humphrey, 1998). This uncertainty of the age of identified reflection horizons may limit the usefulness of common-offset GPR data in mapping variations in accumulation.

Our results show that at $\mathrm{H} 1$ a massive ice layer $\sim 0.5 \mathrm{~m}$ thick extends over the grid area $(20 \mathrm{~m} \times 50 \mathrm{~m})$ at $\sim 4 \mathrm{~m}$ depth. This ice layer may satisfy the conditions for runoff in the percolation zone as they are described by Pfeffer and others (1991). Further, the extent of the ice layer can be mapped easily with GPR. At Crawford Point, however, firn cores showed that there was no laterally extensive ice layer over the grid area $(20 \mathrm{~m} \times 20 \mathrm{~m})$. GPR profiles also showed large holes in internal reflection horizons. This suggests that firn conditions near Crawford Point would not support lateral flow of water over distances greater than tens of meters.

\section{CONCLUSIONS}

The melt/infiltration near Crawford Point creates a complex firn column with lateral heterogeneity over length scales of at least 1.5-14.0 m. This complex stratigraphy makes visual identification of annual layering ambiguous. However, the presence of internal reflection horizons within the GPR grid shows that over the footprint of the radar, lateral homogeneity does exist. This may be due to preferential ice-layer formation at previous summer surfaces (Dunse and others, 2008). Thus, near Crawford Point, although internal reflection horizons are likely isochrones, they do not correlate well with stratigraphic boundaries identified in cores. Further, firn stratigraphy recorded in a single core at Crawford Point is not representative of the firn stratigraphy of the surrounding area $\left(1-5 \mathrm{~km}^{2}\right)$.

The intermittent wetted firn and ice layers observed throughout $>80 \%$ of the core length at $\mathrm{H} 1$ show that wetting fronts propagate through the seasonal snowpack and likely into the underlying firn where they freeze to form ice pipes and ice layers, some of which are $>0.5 \mathrm{~m}$ thick. Here continuous internal reflection horizons correlate with massive ice layers or stratigraphic boundaries between wetted firn and dry firn. Each internal reflection horizon identified at $\mathrm{H} 1$ is separated from other reflection horizons by multiple years of accumulation, so previous summer surfaces are not likely sources for the reflection horizons.

Using common-offset GPR surveys in conjunction with firn or ice cores to map variations in accumulation rates is more difficult in the percolation zone than in the dry-snow facies. Near Crawford Point, radar propagation velocities vary over short distances. Therefore, spatial smoothing of traces and multiple velocity estimates are needed to measure more accurately the average depth to the isochronal internal reflection horizons. Near $\mathrm{H} 1$, a single core is likely representative of the surrounding area $\left(1-5 \mathrm{~km}^{2}\right)$. Internal reflection horizons are likely from multi-annual horizons, so dating of the firn cores is needed to determine age to the reflecting horizons. Where annual signals in the firn are obscured by melting, accurate mapping of variations in accumulation will be ambiguous.

\section{ACKNOWLEDGEMENTS}

This work was funded by US National Science Foundation grant OPP-ANS 0612506. We thank two anonymous reviewers for their insightful comments which greatly improved the manuscript.

\section{REFERENCES}

Annan, A.P. and S.W. Cosway. 1992. Ground penetrating radar survey design. In Proceedings of the Symposium on the Application of Geophysics to Environmental and Engineering Problems (SAGEEP), 26-29 April 1992, Oakbrook, Illinois. Denver, CO, Environmental and Engineering Geophysical Society, 329-351.

Arcone, S.A., V.B. Spikes, G.S. Hamilton and P.A. Mayewski. 2004. Stratigraphic continuity in $400 \mathrm{MHz}$ short-pulse radar profiles of firn in West Antarctica. Ann. Glaciol., 39, 195-200.

Bales, R.C. and 8 others. 2009. Annual accumulation for Greenland updated using ice core data developed during 2000-2006 and analysis of daily coastal meteorological data. J. Geophys. Res., 114(D6), D06301. (10.1029/2008JD010600.)

Bamber, J.L., R.L. Layberry and S.P. Gogineni. 2001. A new ice thickness and bed data set for the Greenland ice sheet. 1. Measurement, data reduction, and errors. J. Geophys. Res., 106(D24), 33,773-33,780. 
Benson, C.S. 1960. Stratigraphic studies in the snow and firn of the Greenland ice sheet. (PhD thesis, California Institute of Technology.)

Bøggild, C.E. 2000. Preferential flow and melt water retention in cold snow packs in West-Greenland. Nord. Hydrol., 31(4-5), 287-300.

Braithwaite, R.J., M. Laternser and W.T. Pfeffer. 1994. Variations of near-surface firn density in the lower accumulation area of the Greenland ice sheet, Pâkitsoq, West Greenland. J. Glaciol., 40(136), 477-485.

Dunse, T., O. Eisen, V. Helm, W. Rack, D. Steinhage and V. Parry. 2008. Characteristics and small-scale variability of GPR signals and their relation to snow accumulation in Greenland's percolation zone. J. Glaciol., 54(185), 333-342.

Harper, J.T. and J.H. Bradford. 2003. Snow stratigraphy over a uniform depositional surface: spatial variability and measurement tools. Cold Reg. Sci. Technol., 37(3), 289-298.

Helm, V. and 6 others. 2007. Winter accumulation in the percolation zone of Greenland measured by airborne radar altimeter. Geophys. Res. Lett., 34(6), L06501. (10.1029/2006GL029185.)

Jezek, K.C., P. Gogineni and M. Shanableh. 1994. Radar measurements of melt zones on the Greenland ice sheet. Geophys. Res. Lett., 21(1), 33-36.

Nghiem, S.V., K. Steffen, G. Neumann and R. Huff. 2005. Mapping of ice layer extent and snow accumulation in the percolation zone of the Greenland ice sheet. J. Geophys. Res., 110(F2), F02017. (10.1029/2004JF000234.)

Nyquist, H. 1928. Certain factors in telegraph transmission theory. Trans. Am. Inst. Elec. Eng., 47, 617-644.
Parry, V. and 6 others. 2007. Investigations of meltwater refreezing and density variations in the snowpack and firn within the percolation zone of the Greenland ice sheet. Ann. Glaciol., 46, 61-68.

Pfeffer, W.T. and N.F. Humphrey. 1998. Formation of ice layers by infiltration and refreezing of meltwater. Ann. Glaciol., 26 83-91.

Pfeffer, W.T., M.F. Meier and T.H. Illangasekare. 1991. Retention of Greenland runoff by refreezing: implications for projected future sea level change. J. Geophys. Res., 96(C12), $22,117-22,124$

Scott, J., D. Mair, P. Nienow, V. Parry and E. Morris. 2006a. A ground-based radar backscatter investigation in the percolation zone of the Greenland Ice Sheet. Remote Sens. Environ., 104(4), 361-373.

Scott, J., P. Nienow, V. Parry, D. Mair, E. Morris and D. Wingham. 2006b. The importance of seasonal and annual layers in controlling backscatter to radar altimeters across the percolation zone of an ice sheet. Geophys. Res. Lett., 33(24), L24502. (10.1029/2006GL027974.)

Spikes, V.B., G.S. Hamilton, S.A. Arcone, S. Kaspari and P. Mayewski. 2004. Variability in accumulation rates from GPR profiling on the West Antarctic plateau. Ann. Glaciol., 39, 238-244

Tiuri, M., A. Sihvola, E. Nyfors and M. Hallikaiken. 1984. The complex dielectric constant of snow at microwave frequencies. IEEE J. Ocean. Eng., 9(5), 377-382.

Vaughan, D.G., H.F.J. Corr, C.S.M. Doake and E.D. Waddington. 1999. Distortion of isochronous layers in ice revealed by ground-penetrating radar. Nature, 398(6725), 323-326. 